$C_{\text {Acc }}^{E}$ : External costs of congestion due to traffic accidents $C_{\text {Delay: }}^{E}$ External costs of congestion due to wasted times and delays

$C_{A P}^{E}$ : External costs of congestion due to air pollution

$V O C_{\text {Total }}$ : Additional external operational costs of vehicles

All costs are in Rial/Km. Vehicular operational costs are calculated based on the following relation:

$\mathrm{VOC}_{\text {Total }}=\mathrm{VOC}_{\mathrm{F}}+\mathrm{VOC}_{\mathrm{M}}+\mathrm{VOC}_{\mathrm{S}}$

The elements of operational costs are fuel consumption, periodical services, and repairs. The relation for calculation of costs due to delays is as following:

$$
C_{\text {Delay }}^{E}=\frac{V O T_{T} \times T_{C S} \times\left(T_{C S} \times \beta_{P} \times V_{C S}\right)}{L_{C S}}
$$

VOT Total : The value of time for all trips in Rial/hour

$\mathrm{T}_{\mathrm{CS}}=$ delay in comparison with the average speed in freeway $(70 \mathrm{~km} / \mathrm{h})$

$\beta_{\mathrm{P}}=$ factor related to vehicle occupation (person/veh)

$\mathrm{V}_{\mathrm{CS}}=$ average of traffic volume (veh/h)

$\mathrm{L}_{\mathrm{CS}}=$ total length of the freeway in this study $(\mathrm{km})$

The additional cost of pollution due to congestion is calculated as following:

$$
C_{A P}^{E}=10^{-9} *\left(C_{A P}^{L O S \square E, F}-C_{A P}^{L O S \square D}\right) * P * U_{P}^{I}
$$

$C_{A p}^{E}$ : Additional external cost of pollution

$P$ : Factor of pollution dissipation in passenger cars

$U_{p}^{1}$ : The cost of one metric ton of dissipated pollution in Iran

The additional cost of congestion due to traffic accidents, has been based on a comprehensive study of accident cost performed earlier in Iran.

Applying the abovementioned research method, and assuming 6 hours of congestion in Hemmat freeway in Tehran in a working day, the average total cost of congestion for such working day, has been computed for six different average speeds of 10 to 60 $\mathrm{km} / \mathrm{h}$. The cost related to average speed of $60 \mathrm{~km} / \mathrm{h}$ is equal to 3 396681162 Rial per one kilometre, which is equal to 91802 US Dollar per kilometre.

Calculating the external costs of density with these number of elements that influence on it, and the data used relative to freeways in Tehran (Iran capital) are the specific features and innovations of this paper. The result of this paper is to provide a comprehensive and practical method for calculating the external costs of highway congestion, that with using this information, it is possible to provide the appropriate solutions to invest properly in order to solve this problem.

\section{ENVIRONMENTAL CHANGE TO REDUCE CHILD INJURY IN LOW AND MIDDLE INCOME COUNTRIES: A SYSTEMATIC REVIEW}

Santosh Bhatta, Toity Deave, Julie Mytton. University of the West of England, Bristol, United Kingdom

10.1136/injuryprev-2016-042156.608

Background Injuries sustained in the home are a significant contributor to the burden of death and disabilities among young children especially those living in Low and Middle Income Countries (LMICs). The objective of this review was to identify and evaluate the effectiveness of environmental change interventions to reduce child injuries and injury hazards in the home in LMICs. Methods Seven electronic databases were searched for randomised controlled trials (RCTs) and controlled before and after (CBA) studies of environmental change interventions designed to reduce child injuries and home hazards and published up to 1 April 2014. Where possible, meta-analysis was conducted using RevMan 5.

Results In total four studies were included in the review. Only one study (CBA) reported child injury and three studies (RCTs) home hazards. In the CBA study, child resistant containers were found effective to reduce the incidence of paraffin ingestion by $47 \%$ during the intervention period and by $50 \%$ after the intervention. Data from two RCTs pooled in a meta-analysis found that a multifactorial intervention (home inspection, safety education and safety device) significantly reduced the post intervention mean scores in the intervention group for poisoning hazards (Mean Difference (MD) -0.77 ; 95\% CI: $-1.36,-0.19$ ) and burn related unsafe practices (MD -0.37 ; 95\% CI: -0.66 , -0.09 ) but not for fall, electrical and paraffin burn hazards. The intervention (home inspection and safety education, not safety device) used in a single RCT significantly reduced the post-intervention mean scores in the intervention group for fall hazards (MD -0.5 ; 95\% CI $-0.66,-0.33$ ) but not for ingestion hazards. Conclusions There is limited evidence to determine if environmental change interventions reduce child injuries but some evidence suggested that they may reduce home hazards. More evidence is needed to determine if altering the physical home environment by removing potential hazards reduces injuries.

\section{ESCALATOR-RELATED INJURIES AGAINST PRESCHOOLERS: AN IN-DEPTH INVESTIGATION IN GUANGDONG PROVINCE, CHINA}

Zuhui Chen, Junfang Xian. First Affiliated Hospital of Jinan University, 613 West Huangpu Avenue, Guangzhou, China

\subsection{6/injuryprev-2016-042156.609}

Background Escalator appears more and more in urban public areas like tube, mall, and some sorts of entertainment venue in recent years accompanied by the modernization of Guangdong Province, China. We benefit facilities but suffer injuries simultaneously from it. Preschoolers are more vulnerable to injuries since they have poor recognition capability of danger. How do escalator-related injuries against preschoolers go like?

Methods From all 56 escalator-related injury accidents happened in Guangdong province at the fewest with one child victim aged 12 or below from the year of 2011 to 2014 by having recourse to the local Media who ever reported them, we succeeded in capturing 43 eligible so as to investigate in depth subsequently. Data inputting and analyses were based on the social statistic software SPSS 20.0 to describe the characteristics epidemiologically of escalator-related injury accidents.

Results There were 47 preschoolers in 43 escalator-related injury accidents totally. Victims went to different outcomes like death 2 , finger loss 18, scalp or skin elsewhere laceration 33, soft tissue contusion 25 , bone fracture 4 , functional deformity 28 , and posttraumatic stress disorder 12. Mal-dressing was the main direct cause $(53.12 \%)$ to escalator-related injuries among all victims including slippers, any dress or backpack with cord. Other causes 
contained playing with the rolling belt $(26.26 \%)$, too long hair or skirt (16.36\%), tread for power cut or other reasons $(4.26 \%)$. Accident area concentrated near the entrance or exit of escalator $(88.37 \%)$ and only 5 happened in the middle of the stairway following a tread (11.63\%).

Conclusions Escalator-related injuries to preschoolers damaged seriously in Guangdong Province, China. Better design for this electric equipment, adequate attention and safety education from families, and reasonable labels or notices around the site, are multilateral intervention approaches. They might help.

\section{A CASE OF LEAD POISONING TO AN ACTION OF BLOOD LEAD LEVEL SCREENING IN CHILDREN IN KRATUMBAN, THAILAND}

Chatchai Im-arom, Athipat Athipongarporn, Adisak Plitponkarnpim. Mahidol University, Bangkok, Thailand

\subsection{6/injuryprev-2016-042156.610}

Background Lead has known as the heavy metal which could be harmful to several human organs such as brain, bone marrow and kidneys. In 2012, an 8 month-old girl was admitted to PICU due to status epilepticus and has been diagnosed with Lead Poisoning with the Blood Lead Level (BLL) of $166 \mathrm{mcg} / \mathrm{dL}$. Then we conducted the field investigation and also checked the BLL of students and children living nearby who might have been at risk of poisoning.

Methods The sample of clothes, floor mat, tap water, dust and wall-paint in the room were collected and tested for Lead level, including the "earth" from the "big bag" which has been stored in the recycled-warehouse where the index case lived.

Three Primary Schools and 2 Child Centres which locate within the distance of $10 \mathrm{~km}$ from the index case were selected and divided into two groups; group A consists of 2 Schools and 1 Child Centre located around $3 \mathrm{~km}$ from the warehouse and group B consists of 1 School and 1 Child Centre which located 9 $\mathrm{km}$ away. Students and children with total number of 234 (222 children, 12 adults) were performed the BLL test and those whose the result of BLL is equal or higher than $10 \mathrm{mcg} / \mathrm{dL}$ will be classified as "High BLL" and those whose the result of BLL is lower than $10 \mathrm{mcg} / \mathrm{dL}$ will be classified as "Non-high BLL".

Results The high level of Lead was found in the sample from the girl's clothes and floor mat, and also extremely high in the "earth" from "big bag".

BLL test revealed 68 out of 234 (29.05\%) participants has been categorised as High BLL. Schools and Child Centres in group A which located nearer to the index case has higher percentage of students and children with high BLL comparing to group B (19.8\%-14.1\%).

Conclusions The Lead contamination in the index case could be from several sources. High BLL Students and children who live in Kratumban district is common. Further field investigation should be conducted to identify the source of contamination and BLL should be performed in every school in this area.

\section{SAFE KIDS @ HOME-A SURVEY ON CHINESE FAMILIES' PERSPECTIVES ON INDOOR AIR QUALITY AT HOME}

Fannie Wang, Roger Zhang, Mulder Wang, Lisa Li, Lydia Lu, Monica Cui. Safe Kids China, Honeywell China

10.1136/injuryprev-2016-042156.611
Background WHO put air pollution is one of the largest environmental risks, but people are more concerned about Outdoor Air Quality (OAQ) but little about Indoor Air Quality (IAQ). People's indoor activities accounts $70 \%$ to $90 \%$ time of a day. Children may stay longer. This survey is to learn Chinese families perspectives on IAQ, identify knowledge and behaviour gap and collect insights on IAQ promotion.

Methods 10 cities were selected based on geography and year average PM2.5. 100 school-aged children's families participated the survey in each city. Data from 1000 school-aged children was collected through school teachers. Children marked their choices on the questionnaire sheets while teacher reading the questions and choices. Data from 1000 parents was collected online. Parents got an survey invitation with online survey links, they completed the online survey and returned a signed feedback slip to school teacher.

Results $80 \%$ of the families consider OAQ as "worse". A limited knowledge of PM 2.5 and its impact, such as 31\% of kids have NEVER heard about the word PM 2.5 and 54\% of parent do not know the "safety level" of indoor PM 2.5 by WHO. Chemicals, bacteria and viruses are the most concerned ingredients on IAQ at home. An obvious gap between knowing and doing, such as smoking was rated as No. 1 bad for IAQ at home (72\%), but $58 \%$ of the parents were observed smoking at home. High consensus on improving IAQ at home with $87 \%$ families supporting actions on No Smoking, Ventilation, Green-materials for decoration and More greenery.

Conclusions The awareness on IAQ low while the need on IAQ is high. An obvious gap between knowing and doing on smoking at home. Great opportunities to conduct IAQ at home with majority families' support especially actions on No Smoking, Ventilation, Green-materials for decoration and more Greenery.

\section{THE EFFECT OF HOUSEHOLD SIZE ON INJURY RISK FACTORS IN SOUTHERN BRAZIL}

${ }^{1}$ Nicole Toomey, ${ }^{1}$ Deena El-Gabri, ${ }^{1,2}$ João Ricardo Vissoci, ${ }^{1,3}$ Catherine Staton. ${ }^{1}$ Duke Global Health Institute; ${ }^{2}$ Faculdade Ingá; ${ }^{3}$ Duke University Medical Centre

\subsection{6/injuryprev-2016-042156.612}

Background The neighbourhood an individual lives in affects their injury risk. In Brazil, males of minority races with low education have the highest risk for injury. Family is an important aspect of Brazilian culture; however there is little research on how family structure affects injury risk. This preliminary analysis investigates the association between household size and risk for types of injuries.

Methods Information on household demographics was collected in a survey on treatment-seeking behaviour following injury in Maringá, Brazil between May and September 2015. The prevalence of demographic factors, including insurance status, mode of transportation to health care, and education level, as well as reasons for not seeking care, were analysed by three categories of household size: 2 or fewer individuals, 3 to 5 individuals, and 6 or more individuals. Frequencies, range, and odds ratios were reported.

Results Of 2678 households, the mean household size was 3.39 (r 1-15). As household size increased, enrollment in private insurance decreased; $50.5 \%$ of households of 2 or fewer had private insurance compared to only $27.5 \%$ with 6 or more. Alcohol usage prior to injury increased with household size; $5.3 \%$ of individuals in households of 2 or fewer reporting use, compared and 